\title{
Regional air-quality forecasting for the Pacific Northwest using MOPITT/TERRA assimilated carbon monoxide MOZART-4 forecasts as a near real-time boundary condition
}

\author{
F. L. Herron-Thorpe ${ }^{1}$, G. H. Mount ${ }^{1}$, L. K. Emmons ${ }^{2}$, B. K. Lamb ${ }^{1}$, S. H. Chung ${ }^{1}$, and J. K. Vaughan ${ }^{1}$ \\ ${ }^{1}$ Department of Civil \& Environmental Engineering, Washington State University, USA \\ ${ }^{2}$ National Center for Atmospheric Research, Boulder, CO, USA \\ Correspondence to: F. L. Herron-Thorpe (farrenthorpe@wsu.edu)
}

Received: 10 December 2011 - Published in Atmos. Chem. Phys. Discuss.: 2 February 2012

Revised: 31 May 2012 - Accepted: 1 June 2012 - Published: 28 June 2012

\begin{abstract}
Results from a regional air quality forecast model, AIRPACT-3, were compared to AIRS carbon monoxide column densities for the spring of 2010 over the Pacific Northwest. AIRPACT-3 column densities showed high correlation $(R>0.9)$ but were significantly biased $(\sim 25 \%)$ with consistent under-predictions for spring months when there is significant transport from Asia. The AIRPACT-3 CO bias relative to AIRS was eliminated by incorporating dynamic boundary conditions derived from NCAR's MOZART forecasts with assimilated MOPITT carbon monoxide. Changes in ozonerelated boundary conditions derived from MOZART forecasts are also discussed and found to affect background levels by \pm 10 ppb but not found to significantly affect peak ozone surface concentrations.
\end{abstract}

\section{Introduction}

Carbon monoxide (CO) is emitted into the atmosphere from the incomplete combustion of hydrocarbons and industrial processes such as iron smelting. $\mathrm{CO}$ is regulated as an EPA criteria pollutant because of its direct adverse effects on human health. It also indirectly affects air quality through reactions with other species in the atmosphere. $\mathrm{CO}$ reacts with the hydroxyl radical $(\mathrm{OH})$, and can lead to increases in tropospheric ozone in the presence of $\mathrm{NO}_{\mathrm{x}}\left(\mathrm{NO}+\mathrm{NO}_{2}\right)$. In the past few decades, catalytic converters on automobiles have significantly reduced $\mathrm{CO}$ emissions by catalytic oxidation to $\mathrm{CO}_{2}$. However, because the lifetime of $\mathrm{CO}$ can be several weeks (Yienger et al., 2000; Jaffe et al., 2001), increased
$\mathrm{CO}$ events can occur along the west coast of the US due to transport of polluted air masses across the Pacific Ocean from industrialized Asian cities (Jaffe et al., 2001). Frontal lifting allows the export of pollution from Asia via the free troposphere (Liu et al., 2003; Liang et al., 2004). This phenomenon has been shown to be most influential during the spring due to stronger cyclones and westerly winds (Liang et al., 2004). This inter-continental transport of polluted air masses is potentially a significant air quality issue for the western US.

State agencies are required by the US EPA to report the sources of air pollutants in the region and relevant surface monitor concentrations. Air quality models help those state agencies understand air quality dynamics and gain understanding of expected concentrations in areas without monitors. Chemical boundary conditions to the models are usually provided in the form of time-independent concentrations based on limited set of observations or climatological monthly profiles developed from global chemistry transport models (GCTM). However, these boundary conditions do not contain the day-to-day variability in long-transport that can affect air quality within the simulation domain. GCTMs such as the Model of OZone And Related Tracers, version 4 (MOZART-4; Emmons et al., 2010) can provide daily forecasts of Pacific transport to specify chemical boundary conditions for the western US. The National Center for Atmospheric Research (NCAR) currently produces MOZART-4 global chemical forecasts that include the assimilation of $\mathrm{CO}$ column retrievals from the Measurement Of Pollution In The Troposphere (MOPITT) satellite instrument. 
The treatment of boundary conditions can be a large source of uncertainty in an air quality model since the boundary conditions essentially act as a continual source of pollutants to the modeling domain. Tang et al. (2007) analyzed several global models for the International Consortium for Atmospheric Research on Transport and Transformation (ICARTT) campaign to test the impact of boundary conditions derived from global models on regional US model predictions. They identified the time-varied external signals as the largest benefit to the regional predictions, because events such as biomass burning and Asian air mass inflow could be adequately modeled. However, differing configurations of global models were found to be a major source of uncertainty in the regional-scale predictions. Tang et al. (2007) found that the mean ozone distributions below $3 \mathrm{~km}$ were insensitive to boundary conditions derived from global models, while values in the mid to upper troposphere were dominated by them. This was attributed to the fact that ozone processes in the lower troposphere are normally dominated by local emissions and chemistry. Zhang et al. (2008) found that Asian pollution enhanced surface ozone concentrations by 5-7 ppbv over western North America in spring 2006 and that these enhancement levels were primarily due to background ozone rather than to episodic pollution events. Jaffe et al. (2003) showed that background ozone in the western USA has increased $\sim 10$ ppbv between 1984 and 2002, which corresponds to a mean trend of $0.26 \mathrm{ppbv}$ per year (Jaffe and Ray, 2007).

Tang et al. (2007) found that regional model predictions of $\mathrm{CO}$ at both high altitudes and at the surface are sensitive to changes in boundary conditions from global models. Ozone and carbon monoxide are often well correlated in pollution plumes over the Pacific in the free troposphere but increased ozone is not observed at the surface except at highelevation sites (Goldstein et al., 2004; Jaffe et al., 2005). Tang et al. (2007) suggest that the use of boundary conditions derived from global models can improve regional air quality predictions and would benefit from data assimilation methods to better constrain the global models.

This paper has four overall goals: (1) to quantify the effect of using NCAR's MOZART-4 forecasts with assimilated MOPITT carbon monoxide as a dynamic boundary condition for AIRPACT-3, a regional air quality forecasting system for the Pacific Northwest, focusing on long-lived species that can be transported large distances; (2) to assess the concentrations of CO coming across the Pacific that influenced the AIRPACT-3 domain in the spring of 2010; (3) to evaluate AIRPACT-3 CO performance using the AIRS/Aqua carbon monoxide satellite product; and (4) to determine the influence that the new dynamic boundary conditions have on AIRPACT-3's ozone simulations.

\section{Methods}

\subsection{AIRPACT-3}

The Air Indicator Report for Public Access and Community Tracking v.3 (AIRPACT-3) is a numerical air-quality forecast system for the Pacific Northwest reporting to the public daily via the web. The AIRPACT-3 system combines atmospheric chemistry and meteorology using community modeling software including the Weather Research and Forecasting (WRF; Skamarock et al., 2005) meteorological model, the SMOKE (Houyoux et al., 2005) emission processing system, and the Community Multi-scale Air Quality Model (CMAQ). The governing equations of CMAQ can be found in Byun and Schere (2006), which describes the calculations for advection, diffusion, chemical reactions, photolysis, cloud mixing, aerosol dynamics, and deposition. The AIRPACT-3 domain (shown in Fig. 1) uses $95 \times 95$ (9025 total) $12 \times 12 \mathrm{~km}$ grid cells and 21 vertical layers with layer thickness increasing from the surface to the tropopause. Further details describing AIRPACT-3 and recent evaluation results using surface monitors are given in Chen et al. (2008). Daily forecasts and archives, along with automated evaluation results based upon AIRNow monitoring data, are provided on the AIRPACT-3 web site (http://lar.wsu.edu/airpact).

In AIRPACT-3, the SMOKE tool is used to process anthropogenic emission categories for each forecast simulation. Area and non-road mobile emissions are based on the 2002 EPA National Emission Inventory (NEI) adjusted to 2005 using the EPA's Economic Growth Analysis System (EGAS) software. On-road mobile emissions are generated using emission factors from the EPA MOBILE v6.2 model and state-specific activity data and are adjusted for WRF-forecast temperature. Anthropogenic emissions over the provinces of British Columbia and Alberta, Canada are included from the 2000 Greater Vancouver Regional District (GVRD) inventory.

Until February 2011, AIRPACT-3 used monthly-averaged chemical boundary conditions (BCON) derived from MOZART-2 simulations (Horowitz, 2006). These boundary conditions were obtained through the downscaling of the MOZART-2 output (version 2.4) global chemical transport model. In these MOZART-2 simulations, historical and projected changes in emissions were included but feedbacks from climate change and trends in stratospheric ozone were ignored. These monthly boundary conditions were calculated by averaging daily simulations for the year 2000 using the Intergovernmental Panel on Climate Change Special Report on Emission Scenarios (IPCC SRES), scenario A2. On 1 March 2011 AIRPACT-3 switched to dynamic boundary conditions derived from daily MOZART-4 forecasts with assimilated MOPITT CO simulated at NCAR. For the purposes of this paper, simulations using the old monthly boundary conditions are referred to as "original AIRPACT-3"; 


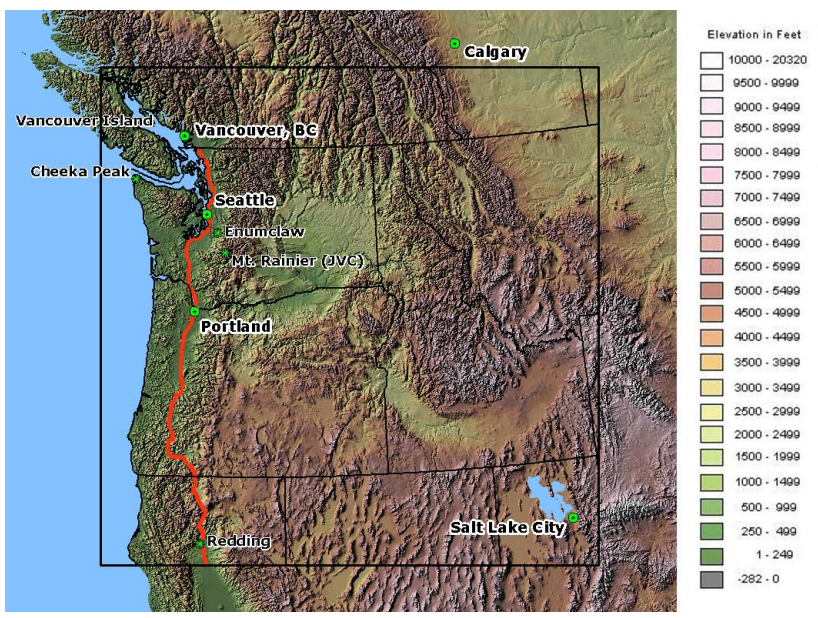

Fig. 1. Elevation in the AIRPACT-3 domain and US Interstate Route 5 drawn as orange line. The domain includes Washington, Idaho, and Oregon with partial inclusion of California, Nevada, Utah, Montana, Wyoming, British Columbia, and Alberta.

and simulations using dynamic boundary conditions derived from MOZART-4 are referred to as "AIRPACT-3 MBC".

For the period of analysis presented here, AIRPACT- 3 employed WRF meteorological forecast fields provided by colleagues at the University of Washington (Mass et al., 2003; http://www.atmos.washington.edu/mm5rt/). The 38 layers provided in these meteorological fields were interpolated to the 21 vertical layers used by AIRPACT-3, with minimal layer collapsing from the surface to $\sim 700 \mathrm{mb}$ and collapsing of three WRF layers per AIRPACT-3 layers above $\sim 700 \mathrm{mb}$. The AIRPACT-3 vertical levels are coincident with the WRF levels to help ensure reasonable mass conservation (Otte and Pleim, 2010). Daily AIRPACT-3 forecasts provide hourly trace gas mixing ratios which are converted to a vertical column density (VCD) and summed vertically for direct comparison to tropospheric column density satellite retrievals, as described in Herron-Thorpe et al. (2010).

In order to properly compare the static model grid to varying satellite grids, the AIRPACT- 3 cells that fall within the spatial boundaries of each satellite pixel are averaged, effectively reducing the resolution of the model results to equal that of the satellite, and then interpolated back to the AIRPACT-3 grid through use of a Delaunay triangulation scheme.

\subsection{MOPITT: Measurement Of Pollution In The Troposphere}

MOPITT is a gas-correlation radiometer on-board the NASA Terra satellite launched in 1999. Satellite overpass in northern mid-latitudes occurs twice daily at $\sim 10: 15$ a.m. (descending) and $\sim 10: 45$ p.m. (ascending) local time. Carbon monoxide is retrieved from the observed radiances using a maximum a posteriori (MAP) algorithm (e.g. Rodgers,

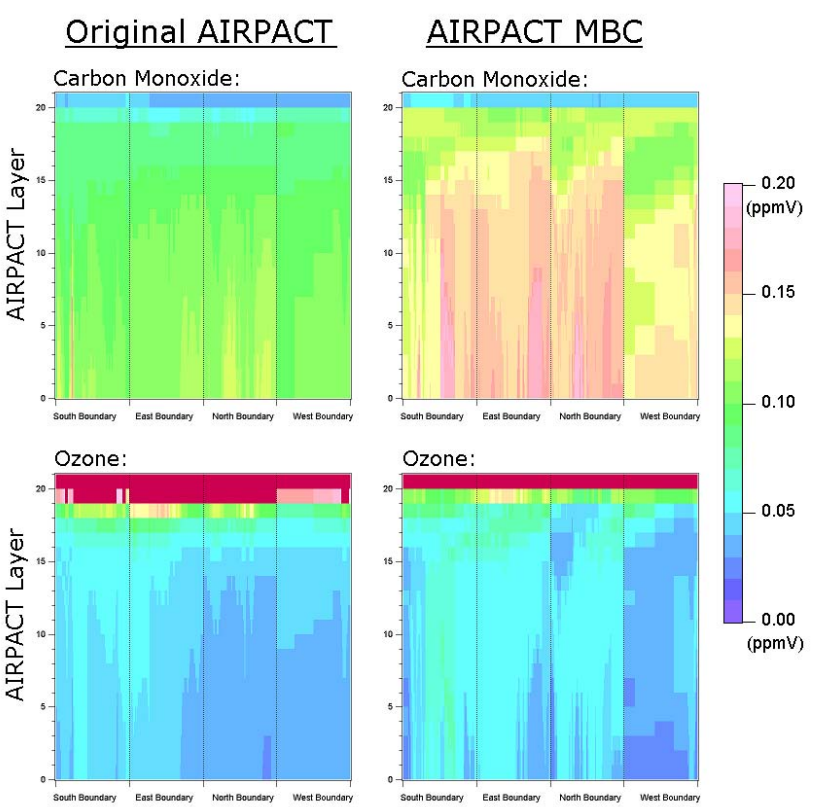

Fig. 2. Typical nighttime carbon monoxide and ozone boundary conditions for the original AIRPACT-3 BCON (left) and the updated dynamic boundary conditions (right). 16 May 2010 is shown.

2000). The V4 retrievals of CO, based on the thermal infrared channels, are available from March 2000 through the present both as total column amount and as mixing ratio profiles at 10 levels, for each geo-located $22 \times 22 \mathrm{~km}$ pixel (Deeter et al., 2010).

\subsection{MOZART: Model of OZone And Related Tracers}

The MOZART GCTM is built on the framework of the Model of the Atmospheric Transport and Chemistry (MATCH) (Rasch et al., 1997). MOZART-4 has the following upgrades from MOZART-2: the chemical mechanism treats volatile organic compounds (VOCs) with more speciated compounds, online calculations of aerosols are included, photolysis rates take into account aerosols and clouds, albedo changes are derived from Moderate Resolution Imaging Spectroradiometer (MODIS) retrievals, water vapor is calculated from surface moisture flux, nitric oxide (NO) emissions from soil and lightning have been updated, and upper and lower boundary conditions are better constrained. Horowitz et al. (2003) gives a detailed description of MOZART-2 while Emmons et al. (2010) gives a detailed description of MOZART-4 and how it differs from MOZART-2. The MOZART-2 simulations used the EDGAR-2 emissions inventory (with climatological fire emissions) for the year 2000, while the MOZART- 4 forecasts (for the results shown here for 2010) use the anthropogenic inventory representative of 2008 developed by D. Streets and Q. Zhang (http://www. cgrer.uiowa.edu/arctas/emission.html), with fire emissions as described in Sect. 2.4. 
Table 1. Summary of 02:00 p.m. (top) and 02:00 a.m. (bottom) carbon monoxide VCD for AIRPACT-3 vs. AIRS (All times are in Pacific Standard Time).

\begin{tabular}{|c|c|c|c|c|}
\hline & $(r)$ Linear Correlation & Avg. AIRS $\left(\right.$ molec $\left.\mathrm{cm}^{-2}\right)$ & Avg. Model Bias (\%) & Avg. AIRPACT-3 \\
\hline \multicolumn{5}{|c|}{ AIRPACT-3 vs. AIRS Summary: 02:00 p.m. } \\
\hline April 2010 & 0.93 & $2.1 \times 10^{18}$ & $-25.2 \%$ & $1.6 \times 10^{18}$ \\
\hline May 2010 & 0.93 & $2.0 \times 10^{18}$ & $-28.4 \%$ & $1.4 \times 10^{18}$ \\
\hline April 2010 (w/AK) & 0.93 & $2.1 \times 10^{18}$ & $-26.4 \%$ & $1.6 \times 10^{18}$ \\
\hline May 2010 (w/AK) & 0.92 & $2.0 \times 10^{18}$ & $-28.3 \%$ & $1.4 \times 10^{18}$ \\
\hline April 2010 (MBC) & 0.93 & $2.1 \times 10^{18}$ & $6.4 \%$ & $2.3 \times 10^{18}$ \\
\hline May 2010 (MBC) & 0.94 & $2.0 \times 10^{18}$ & $6.2 \%$ & $2.1 \times 10^{18}$ \\
\hline April 2010 (MBC w/AK) & 0.90 & $2.1 \times 10^{18}$ & $1.5 \%$ & $2.2 \times 10^{18}$ \\
\hline May $2010($ MBC w/AK) & 0.90 & $2.0 \times 10^{18}$ & $2.8 \%$ & $2.0 \times 10^{18}$ \\
\hline \multicolumn{5}{|c|}{ AIRPACT-3 vs. AIRS Summary: 02:00 a.m. } \\
\hline April 2010 & 0.97 & $2.0 \times 10^{18}$ & $-19.5 \%$ & $1.6 \times 10^{18}$ \\
\hline May 2010 & 0.97 & $1.9 \times 10^{18}$ & $-24.5 \%$ & $1.4 \times 10^{18}$ \\
\hline April 2010 (w/AK) & 0.97 & $2.0 \times 10^{18}$ & $-22.2 \%$ & $1.6 \times 10^{18}$ \\
\hline May 2010 (w/AK) & 0.97 & $1.9 \times 10^{18}$ & $-23.9 \%$ & $1.4 \times 10^{18}$ \\
\hline April 2010 (MBC) & 0.97 & $2.0 \times 10^{18}$ & $13.6 \%$ & $2.3 \times 10^{18}$ \\
\hline May 2010 (MBC) & 0.98 & $1.9 \times 10^{18}$ & $11.7 \%$ & $2.1 \times 10^{18}$ \\
\hline April 2010 (MBC w/AK) & 0.97 & $2.0 \times 10^{18}$ & $-0.1 \%$ & $2.0 \times 10^{18}$ \\
\hline May 2010 (MBC w/AK) & 0.97 & $1.9 \times 10^{18}$ & $-1.7 \%$ & $1.9 \times 10^{18}$ \\
\hline
\end{tabular}

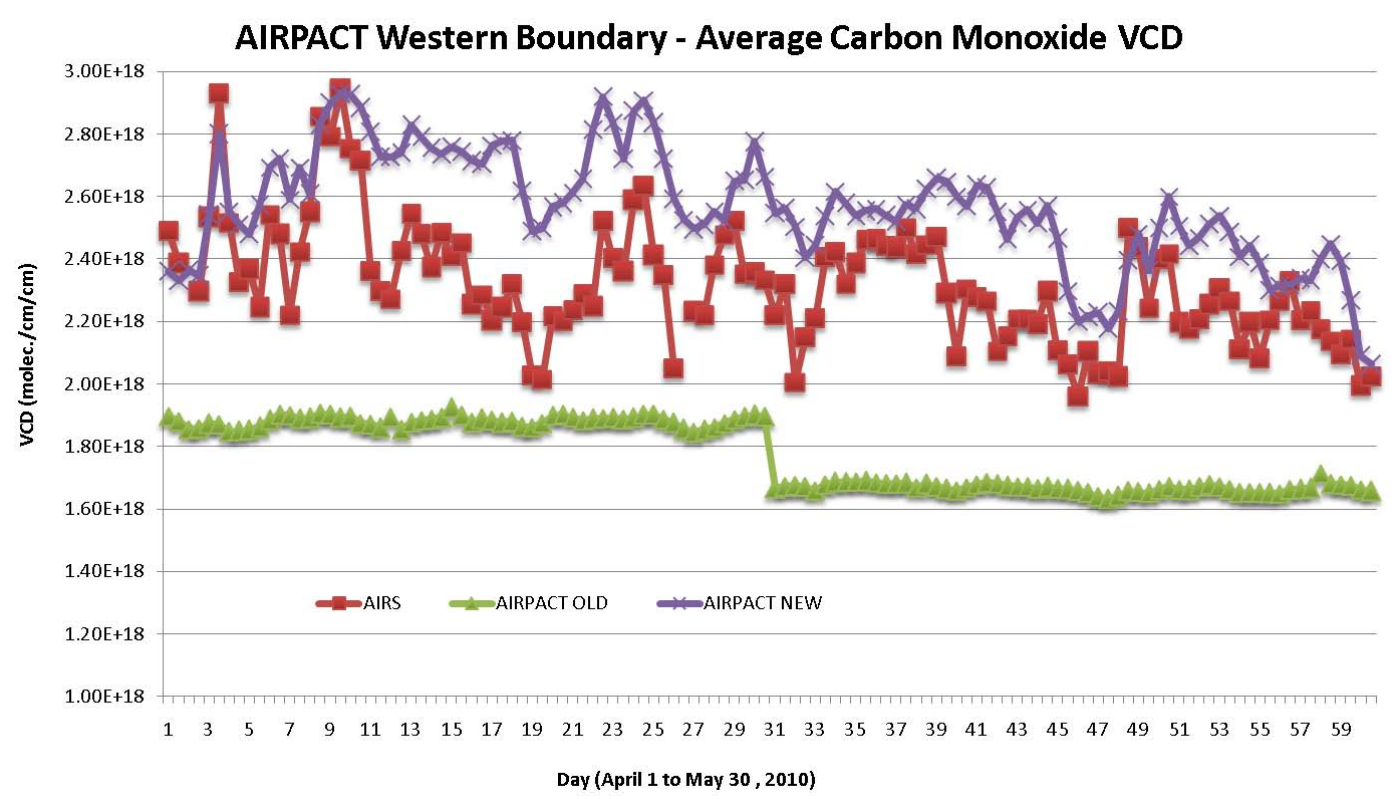

Fig. 3. The average CO VCD along AIRPACT's western boundary during April and May of 2010 for $\sim 02: 00$ p.m. and $\sim 02: 00$ a.m. (PST). 
Daytime Carbon Monoxide Vertical Profiles Along AIRPACT's Western Boundary

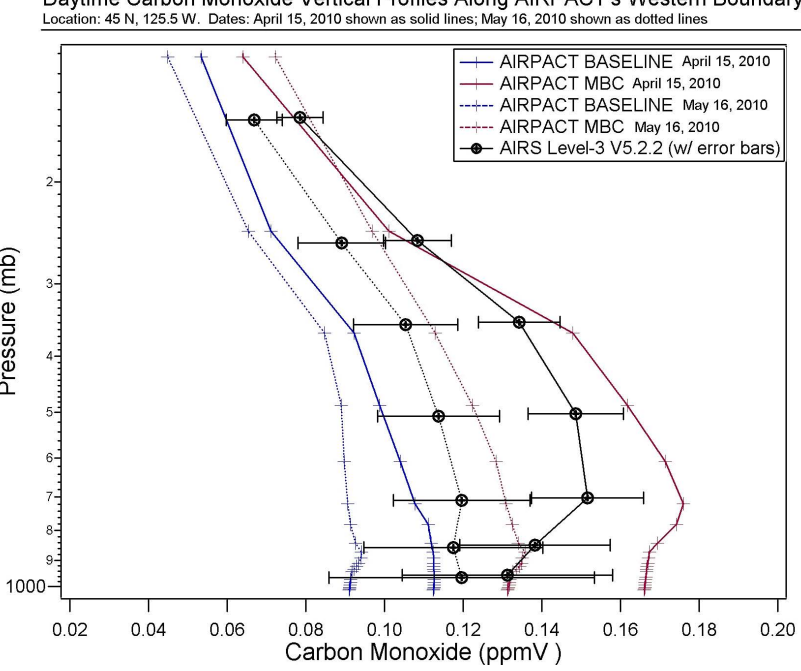

Fig. 4. Carbon monoxide vertical profiles midway along AIRPACT3's western boundary for 15 April (solid lines) and May 16 (dotted lines) at $\sim 02: 00$ p.m (PST).

\subsection{AIRPACT-3's dynamic boundary conditions derived from MOZART-4 forecasts}

NCAR provides MOZART-4 global chemical forecasts (on the web at http://www.acd.ucar.edu/acresp/forecast/) which are driven by National Center for Environmental Prediction (NCEP) Global Forecasting System (GFS) forecast meteorology. These forecasts use fire emissions based on near real-time MODIS fire counts provided by the Fire Information for Resource Management System (FIRMS, http: //earthdata.nasa.gov/data/nrt-data/firms). A monthly climatology of emissions per fire count is scaled by the daily fire counts to give biomass burning emissions estimates. The fire emissions climatology was created from the Global Fire Emissions Database (GFED-v2) (van der Werf et al., 2006) and from monthly total fire counts from MODIS for 20002008 (Al-Saadi et al., 2008). The chemical conditions that AIRPACT-3 receives from MOZART-4 include assimilation of MOPITT CO. CO is assimilated in MOZART-4 as a full reacting species using a suboptimal Kalman Filter technique, as described in Lamarque (2004). The MOPITT and MOZART CO total columns are compared and MOZART-4 $\mathrm{CO}$ profiles are subsequently scaled to match the MOPITT column. The magnitudes of changes in $\mathrm{CO}$ are small but the impact can grow with time.

NCEP/GFS analysis meteorological files become available at $\sim$ 16:00 (Pacific Standard Time (PST)) and are used for the first $24 \mathrm{~h}$ of the MOZART-4 simulations used in this work, which includes assimilation of MOPITT CO. Forecast files are ready for MOZART-4 at $\sim 22: 30$ PST and are used for the remaining $72 \mathrm{~h}$ of the MOZART- 4 simulation, completing at $\sim 07: 00$ the next day. The first $8 \mathrm{~h}$ of the MOZART-4 results are removed, the next 24 are used for AIRPACT-3 boundary condition archives, and the next $64 \mathrm{~h}$ are converted to CMAQ-ready boundary conditions for the AIRPACT-3 operational forecast. The AIRPACT-3 surface forecasts become available each morning at http://lar.wsu.edu/airpact/ with emissions maps and performance charts at surface monitor locations.

\subsection{AIRS: Atmospheric InfraRed Sounder}

The Atmospheric Infra-Red Sounder (AIRS) provides twice daily global observations of carbon monoxide which are used in this study as a source for independent validation of AIRPACT-3's carbon monoxide predictions. AIRS was built by BAE Systems and launched aboard NASA's Aqua satellite in 2002 and orbits as part of the "Afternoon"-Train. AIRS retrieves daily global air and surface temperature, water vapor, cloud properties, carbon monoxide, methane, ozone, and carbon dioxide (http://www-airs.jpl.nasa.gov/). AIRS and AMSU (Advanced Microwave Sounding Unit) were designed to meet the weather prediction requirements of NOAA and the global change research objectives of NASA. AIRS is able to obtain vertical information about its retrievals by detecting the change in spectra of molecules at varying temperatures. Sun-synchronous infrared retrievals are obtained at $\sim 01: 30$ a.m. and $\sim 01: 30$ p.m. local time, with a $1650 \mathrm{~km}$ swath width that nearly allows twice-daily global coverage. The level-2 CO AIRS data is reported on the AMSU ground footprint and varies from 36 to $50 \mathrm{~km}$ in length (along-track), determined by the angle of rotation of the scan mirror along the line of flight. AIRS uses an infrared spectrometer and a visible light/near-infrared photometer. The infrared spectrometer has spectral coverage from 3.74 to $4.61 \mu \mathrm{m}$, from 6.20 to $8.22 \mu \mathrm{m}$, and from 8.8 to $15.4 \mu \mathrm{m}$. The spectrum for $\mathrm{CO}$ is sampled twice per spectral resolution element for 36 channels (Olsen, 2007b). Further information can be found at http://airs.jpl.nasa.gov/technology/.

Both the AIRS level-2 and level-3 products provided useful information for this study. The level-3 product served as a useful tool to quickly plot a large area of the globe and qualitatively understand how $\mathrm{CO}$ is transported across the Pacific. The vertical and horizontal resolution of the level2 product provides a better comparison to the relatively fine resolution of AIRPACT-3. AIRS level-2 data includes a total column and 9 trapezoidal layers of $\mathrm{CO}$ mixing ratio with pressure vertices at 1.25, 41.1, 156, 254, 351, 505, 706, 853, and $960 \mathrm{mb}$ (at sea level). The error in the volume mixing ratio retrievals is large for layers close to the surface, and a fair number of pixels are flagged as poor quality, but overall AIRS provides valuable information about the daily distribution of $\mathrm{CO}$ in the atmosphere. 


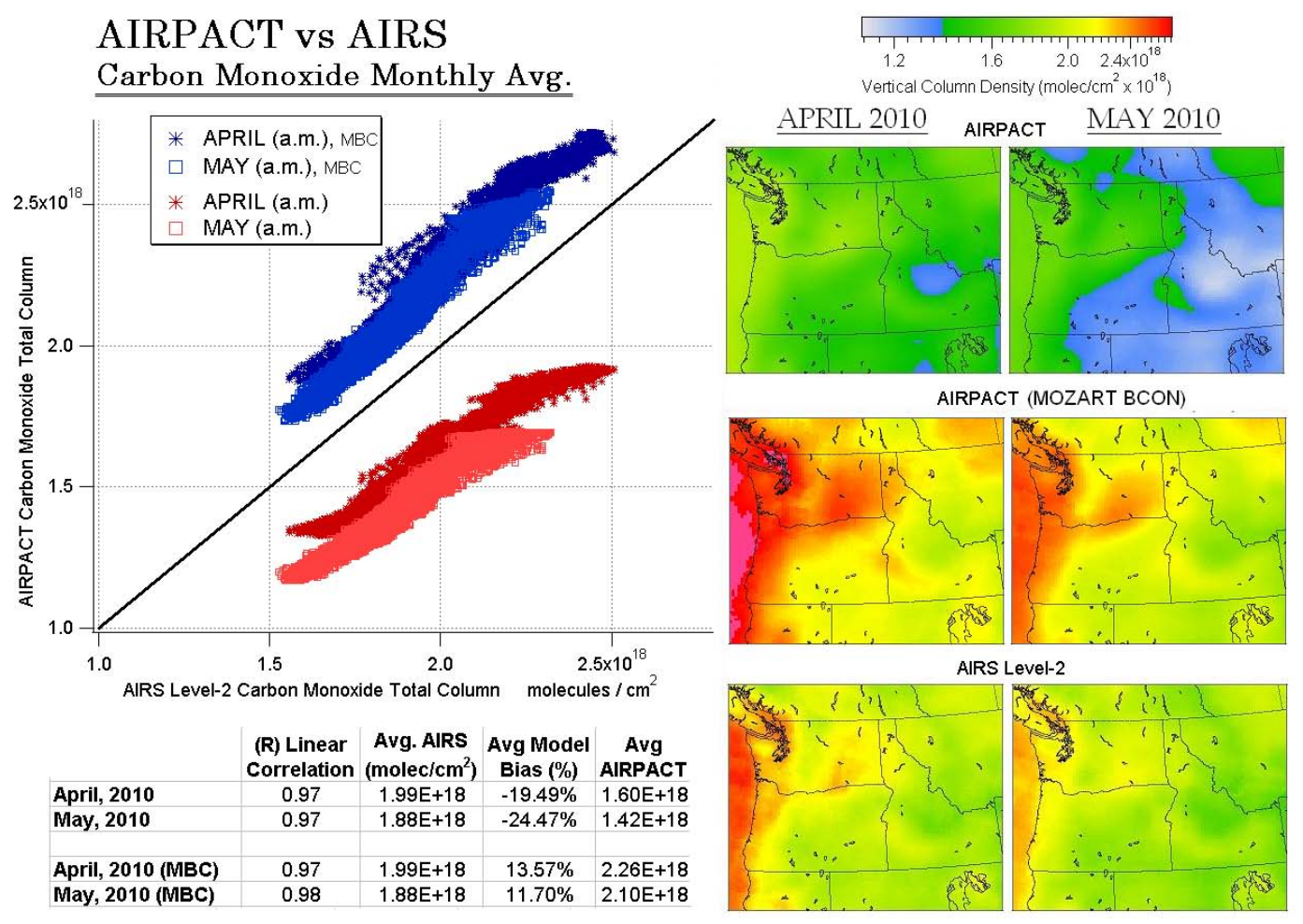

Fig. 5. Nighttime ( 02:00 a.m. PST) carbon monoxide total column monthly averages for April and May of 2010. The linear correlation of AIRPACT-3 vs. AIRS CO is plotted (left) with original AIRPACT-3 in red and MOZART BCON-updated AIRPACT-3 in blue. Corresponding maps of the region (right) show the distribution of $\mathrm{CO}$ across the domain. Note: the AIRS averaging kernels have not been applied to the AIRPACT-3 results.

\subsection{Applying the AIRS averaging kernel to AIRPACT-3 CO forecasts}

An averaging kernel expresses the relative sensitivity of an instrument to the abundance of the target species within the layers throughout the atmospheric column. The instrument averaging kernel should be applied to model results so that modeled columns can be correctly compared to the satellite retrievals. Applying the averaging kernels helps users account for variations in the satellite's response due to changes in geometry, terrain variables, cloud properties, meteorology, and the modeled "first guess" CO profiles for each retrieved pixel. An averaging kernel matrix for each 9-layer profile that AIRS retrieves is available in the AIRS CO support product files. As discussed in Olsen et al. (2007a) and Maddy and Barnet (2008) the averaging kernel is convolved with a model profile by the following:

$\log _{10}\left(\boldsymbol{x}^{\prime}\right)=\log _{10}\left(\boldsymbol{x}_{0}\right)+\mathbf{F A F ^ { \prime }}\left[\log _{10}(\boldsymbol{x})-\log _{10}\left(\boldsymbol{x}_{0}\right)\right]$

where $\boldsymbol{x}$ is the original modeled CO profile, $\boldsymbol{x}^{\prime}$ is the new convolved model profile, $\boldsymbol{x}_{\mathbf{0}}$ is the AIRS "first guess" profile, $\mathbf{F}$ is an overlapping trapezoidal function, $\mathbf{A}$ is the averaging kernel, and $\mathbf{F}^{\prime}$ is the pseudo-inverse of $\mathbf{F}$. $\mathbf{F}$ is a $100 \times 9$ matrix, $\mathbf{A}$ is a $9 \times 9$ matrix, and $\mathbf{F}$ ' is a $9 \times 100$ matrix, and all profiles are 100 element arrays. The AIRS CO first guess pro- file is defined by the MOPITT first guess profile plus the Air Force Geophysical Laboratory profile above $7 \mathrm{mb}$. Convolving model data with the averaging kernel requires the user to vertically interpolate their data to the 100 pressure levels of the first guess profiles used in the algorithms. Furthermore, F is not included in the support product but can be computed offline by the user as a function of the pressure profiles. Coding for this step was developed with support from E. Olsen and E. Maddy (personal communication, 2011). The convolved AIRPACT-3 profiles were also interpolated back to the original 21 AIRPACT-3 layers for calculating the convolved vertical column density.

\section{Results and discussion}

\subsection{Dynamic BCON vs. original BCON for AIRPACT-3}

The Pacific Northwest is sparsely populated and has limited emissions sources. Most of the urban areas modeled by AIRPACT-3 are located far from the domain's boundaries, so the potential for boundary conditions to cause significant change in criteria pollutants is greatest for air pollutants with long atmospheric residence times (e.g. $\mathrm{CO}, \mathrm{O}_{3}$ and PAN). The carbon monoxide in the AIRPACT-3 MBC boundary 


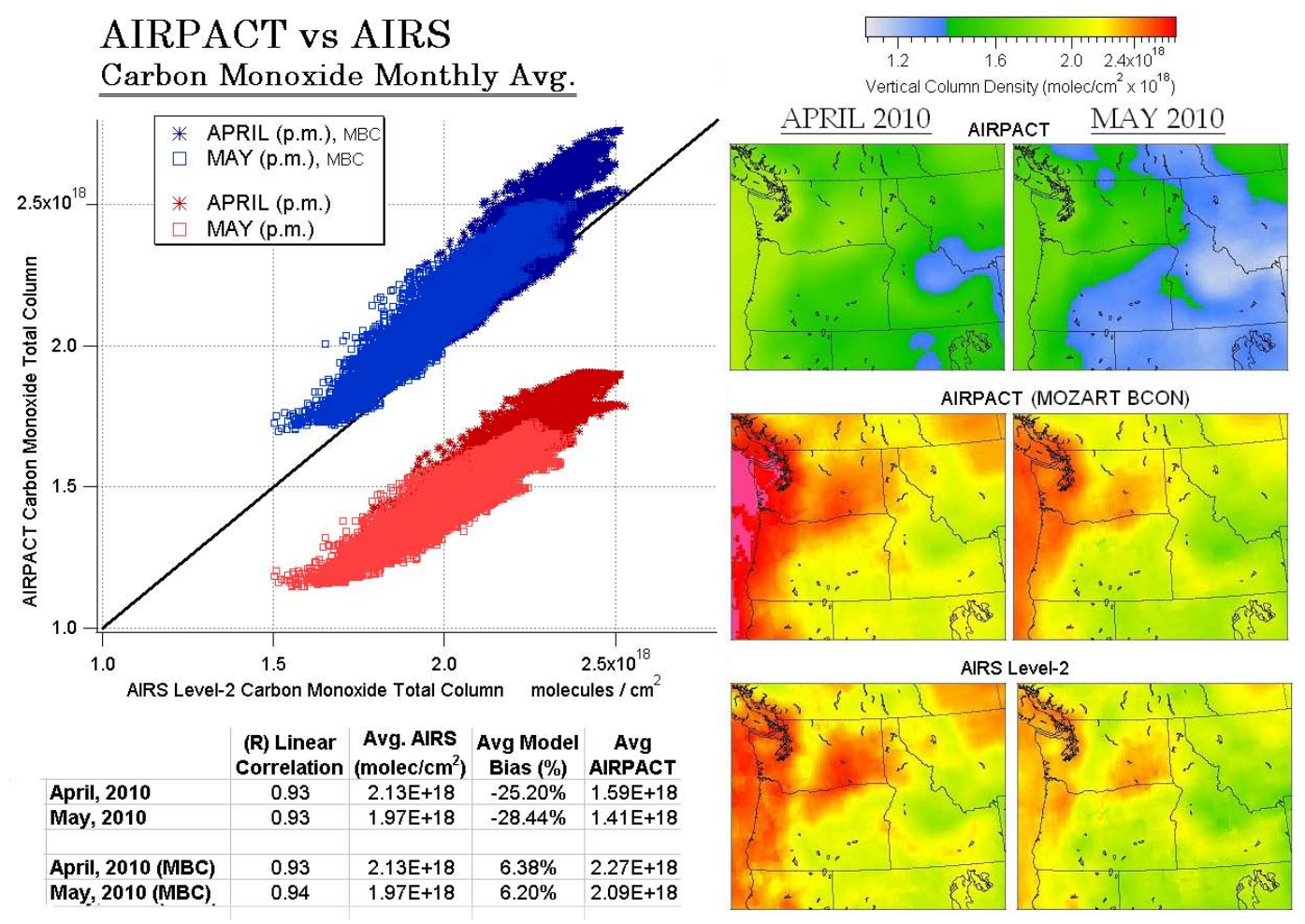

Fig. 6. Daytime ( 02:00 p.m. PST) carbon monoxide total column monthly averages for April and May of 2010. The linear correlation of AIRPACT-3 vs. AIRS CO is plotted (left) with original AIRPACT-3 in red and MOZART BCON-updated AIRPACT-3 in blue. Corresponding maps of the region (right) show the distribution of $\mathrm{CO}$ across the domain. Note: the AIRS averaging kernels have not been applied to the AIRPACT-3 results.

conditions (Fig. 2) is usually $\sim 50 \mathrm{ppbV}$ more in the troposphere than the original AIRPACT-3 boundary conditions, with even greater increases during large Pacific transport events. Tropospheric ozone concentrations in AIRPACT-3's dynamic boundary conditions can increase by $\sim 10$ ppb during Pacific transport events, but concentrations can decrease as well. Furthermore, patterns and peaks of surface ozone concentrations are similar to the original AIRPACT-3 boundary conditions since surface ozone is largely driven by radiation and local emissions.

\subsection{Influence of trans-continental pollution on AIRPACT-3's western boundary}

AIRS retrieved three extremely polluted air masses with an average VCD over $2.6 \times 10^{18}$ molecules $\mathrm{cm}^{-2}$ along the western AIRPACT-3 boundary during April 2010. However, no such extreme events occurred during May 2010. MOZART-4 forecasts with assimilated MOPITT carbon monoxide provided a realistic representation of springtime boundary conditions for the Pacific Northwest. The monthly averaged MOZART- 2 boundary conditions used by the original AIRPACT- 3 contained no periodic pollution events crossing into the domain and were also consistently low on average, whereas the MBC simulations were much more accu- rate, as shown in Fig. 3. During April and May of 2010 the largest differences in MBC AIRPACT-3 CO, as a result of using the dynamic boundary conditions, were on the order of $+50 \mathrm{ppbV}$ and often occurred in the low to mid-troposphere, as shown in Fig. 4.

\subsection{Distribution of CO in the AIRPACT-3 Domain}

The horizontal distribution of CO in both sets of AIRPACT-3 simulations agrees well with AIRS retrievals. In general, the highest VCD values occur along the coast, near AIRPACT3 's western boundary and over the Interstate-5 corridor from Vancouver BC, through Seattle, WA, and down to southern Oregon. Linear correlations for the whole domain are quite high $\left(r^{2}=0.9\right)$ for night and day VCD monthly averages, as shown in Figs. 5 and 6 respectively. The dynamic boundary conditions do not significantly change the linear correlation for the whole domain. The original AIRPACT-3 simulations of column CO are $25 \%$ lower than AIRS retrievals, on average across the whole domain, with larger negative biases during the day. In contrast, the MBC AIRPACT- 3 simulations result in CO columns that are $10 \%$ higher than AIRS retrievals on average across the whole domain, with larger biases during the night. Table 1 summarizes these carbon monoxide column results. 


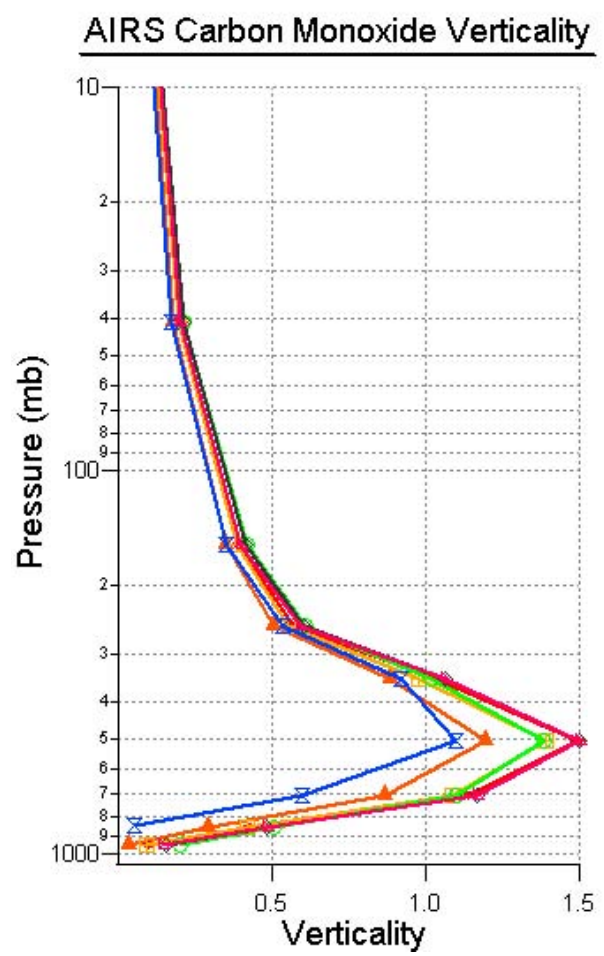

Fig. 7. AIRS carbon monoxide verticality for a few pixels in the Spring of 2010 (separated by color), showing that AIRS has most sensitivity to carbon monoxide in the middle troposphere. When convolving the AIRPACT-3 profiles with the AIRS averaging kernels, portions of the convolved profile where verticality is over 1 typically increase, while they decrease where verticality is less than 1.

The AIRS CO averaging kernels have the largest magnitude in the mid-troposphere, between 700 and $400 \mathrm{mb}$; thus, AIRS has the most sensitivity to $\mathrm{CO}$ in that atmospheric region, represented as the sum of averaging kernels at each pressure level and reported by AIRS as "verticality", shown in Fig. 7. The columns that result after applying the AIRS averaging kernel are less than the pre-convolved columns by a few percent (see Fig. 8), with the largest decreases in column density along the coastal waters and nonpolluted high-elevation areas. The original AIRPACT-3 simulations of column $\mathrm{CO}$ with the averaging kernels applied are $25 \%$ lower than AIRS retrievals, on average across the whole domain, with larger biases during the day. In contrast, the MBC AIRPACT-3 simulations with the averaging kernels applied result in CO columns that are only $1.5 \%$ higher than AIRS retrievals, on average across the whole domain. The AIRPACT-3 MBC simulations convolved with the AIRS averaging kernels typically result in boundary layer values $\sim 50 \mathrm{ppb}$ less than the non-convolved results (see Figs. 912), and have good correlation to the vertical distribution of $\mathrm{CO}$ in AIRS retrievals. The original AIRPACT simulations typically have profiles that are closer to the AIRS first guess profile values and exhibit less change when the averaging kernels are applied.

\subsection{Effects of dynamic boundary conditions on surface ozone}

Modeled surface ozone during April and May of 2010 was directly influenced by the dynamic boundary conditions, especially at sites near the boundary itself. The largest differences between the two model sets of surface ozone occurred at Northern California sites that were immediately influenced by the southern boundary conditions $\left(R^{2}<0.1\right)$. AIRNow sites in this southwestern part of the modeling domain exhibited an average absolute difference of 5-6 ppb of ozone between the original AIRPACT-3 and AIRPACT-3 MBC simulations, which were largely caused by differences in the surface layer of the boundary conditions. Sites further than a few grid cells from the boundary exhibited far less change, especially sites at low elevations. Sites further into the domain that exhibited the most correlation $\left(R^{2}>0.75\right)$ between the two model sets, with changes less than $3.5 \mathrm{ppb}$ of ozone, were all low elevation sites $(H<120 \mathrm{~m})$. Elevation was found to have an inverse relation to the correlation between the two model sets at AIRNOW sites in the domain $\left(R^{2}=0.3\right)$, which can be expected because elevated sites are exposed to more of the polluted air aloft. Timelines of AIRPACT-3, AIRPACT-3 MBC, and AIRNow reported values of ozone during April and May of 2010 are available in the Supplement.

We chose to also model August of 2010, when surface monitor ozone concentrations were highest for the year, in order to assess the impact of dynamic boundary conditions on predicted surface concentrations of summertime ozone during a policy relevant period. Carbon monoxide was significantly higher near the coastline and along the western part of the domain (Fig. 13) in the MBC simulations, with less effect further inland. Figure 14 shows the ozone performance of AIRPACT-3 at 5 AIRNOW sites for an 8-day period. Dynamic boundary conditions led to $5-15$ ppb less simulated surface ozone at most AIRNow locations before the maximum ozone event. However, ozone maximums were very similar across most of the domain, and only after the ozone maximum did MBC simulations rise $5 \mathrm{ppb}$ over the original simulations. In contrast, elevated areas $(H>300 \mathrm{~m})$ near the northwest corner of the domain had higher peak surface ozone in the MBC simulations. The most southern and eastern parts of the domain exhibited different trends during this time period, with significant decreases in surface ozone in the MBC simulations for Redding, CA and very small differences in the Salt Lake City, UT region. These results can be expected since polluted air masses from Asia can often be influenced by regional meteorology, drawing the air masses northerly toward the Alaska coastline where they eventually cross the coastline in a south-easterly direction, typically 


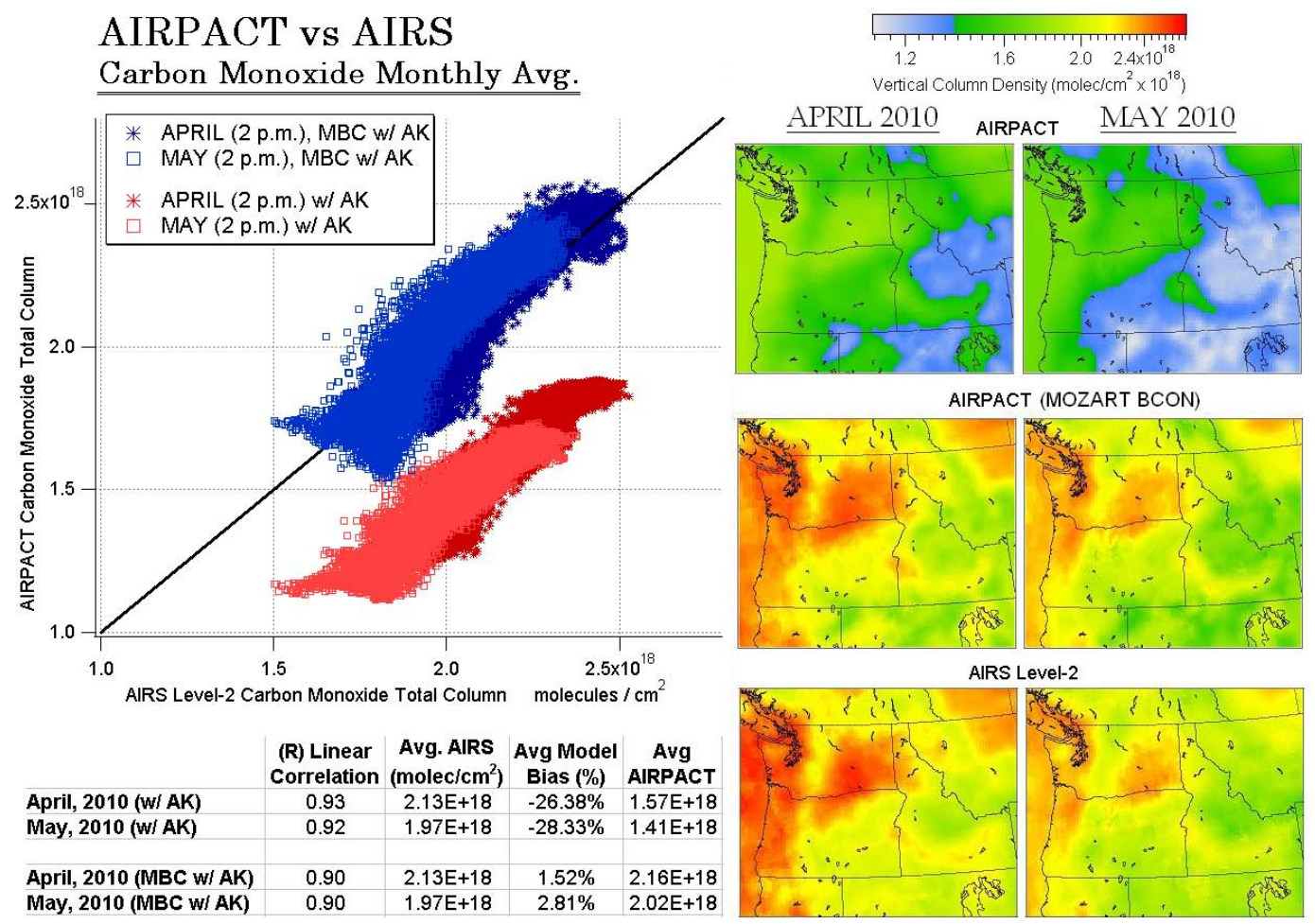

Fig. 8. Daytime ( 02:00 p.m. PST) carbon monoxide total column monthly averages for April and May of 2010 (w/avg. kernels). The linear correlation of AIRPACT-3 vs. AIRS CO is plotted (left) with original AIRPACT-3 in red and MOZART BCON-updated AIRPACT-3 in blue. Corresponding maps of the region (right) show the distribution of $\mathrm{CO}$ across the domain.

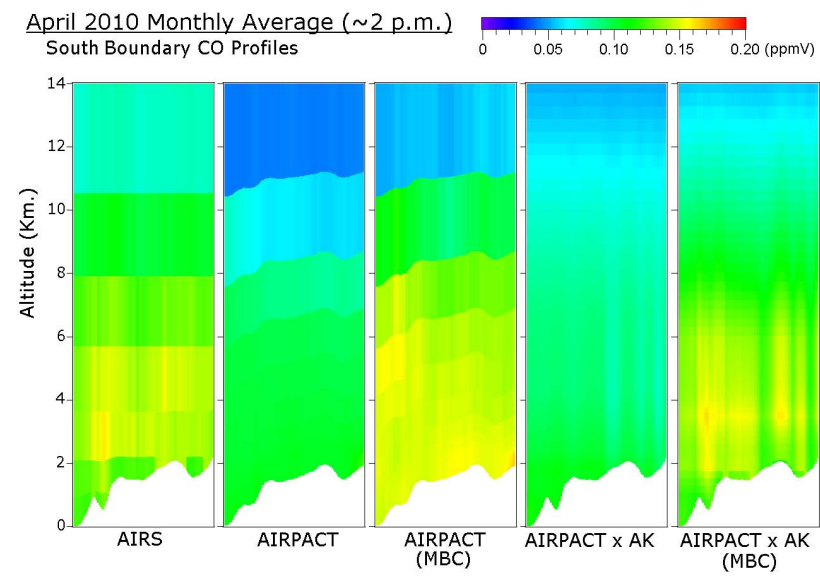

Fig. 9. April 2010 monthly average ( 02:00 p.m. PST) carbon monoxide profiles along the south border of AIRPACT-3 for (a) AIRS level-2 v5, (b) original AIRPACT-3, (c) AIRPACT-3 MBC, (d) original AIRPACT-3 convolved with the AIRS averaging kernel, and (e) AIRPACT-3 MBC convolved with the AIRS averaging kernel. Note that AIRPACT-3 values shown are the predicted CMAQ concentrations, and not boundary conditions themselves. For reference, $\mathrm{x}$-axes run from west to east: offshore northern California (left) to Salt Lake City (right).

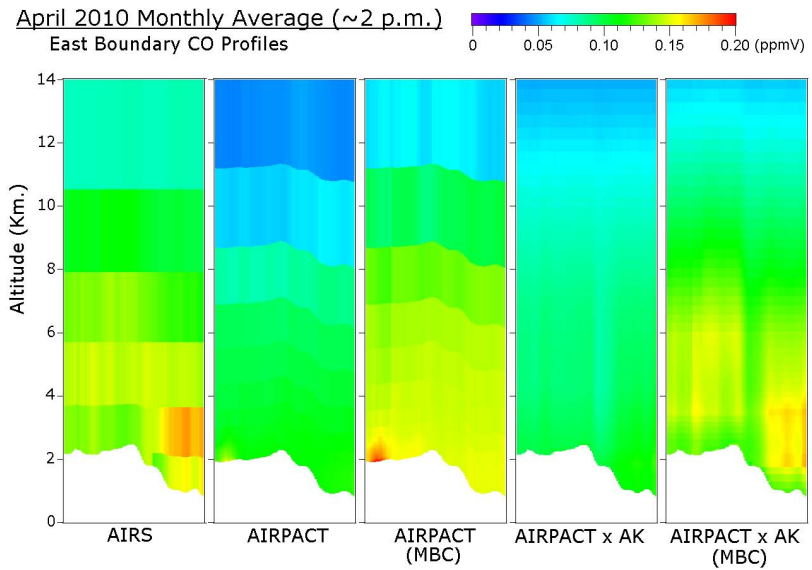

Fig. 10. April 2010 monthly average ( 02:00 p.m. PST) carbon monoxide profiles along the east border of AIRPACT-3 for (a) AIRS level-2 v5, (b) original AIRPACT-3, (c) AIRPACT-3 MBC, (d) original AIRPACT-3 convolved with the AIRS averaging kernel, and (e) AIRPACT-3 MBC convolved with the AIRS averaging kernel. Note that AIRPACT-3 values shown are the predicted CMAQ concentrations, and not boundary conditions themselves. For reference, $\mathrm{x}$-axes run from south to north: Salt Lake City (left) to the Alberta/British Columbia border (right). 


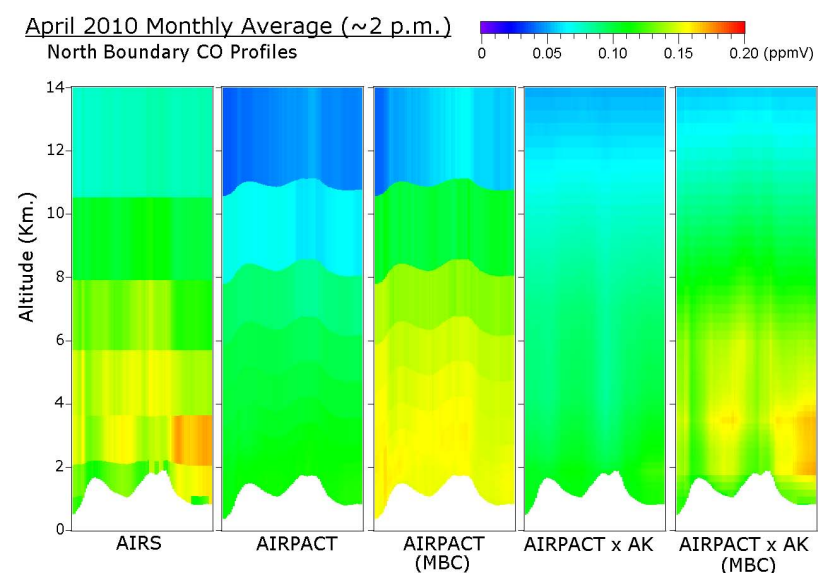

Fig. 11. April 2010 monthly average ( 02:00 p.m. PST) carbon monoxide profiles along the north border of AIRPACT-3 for (a) AIRS level-2 v5, (b) original AIRPACT-3, (c) AIRPACT-3 MBC, (d) original AIRPACT-3 convolved with the AIRS averaging kernel, and (e) AIRPACT-3 MBC convolved with the AIRS averaging kernel. Note that AIRPACT-3 values shown are the predicted CMAQ concentrations, and not boundary conditions themselves. For reference, $\mathrm{x}$-axes run from west to east: Vancouver Island (left) across British Columbia to the Alberta/British Columbia border (right).

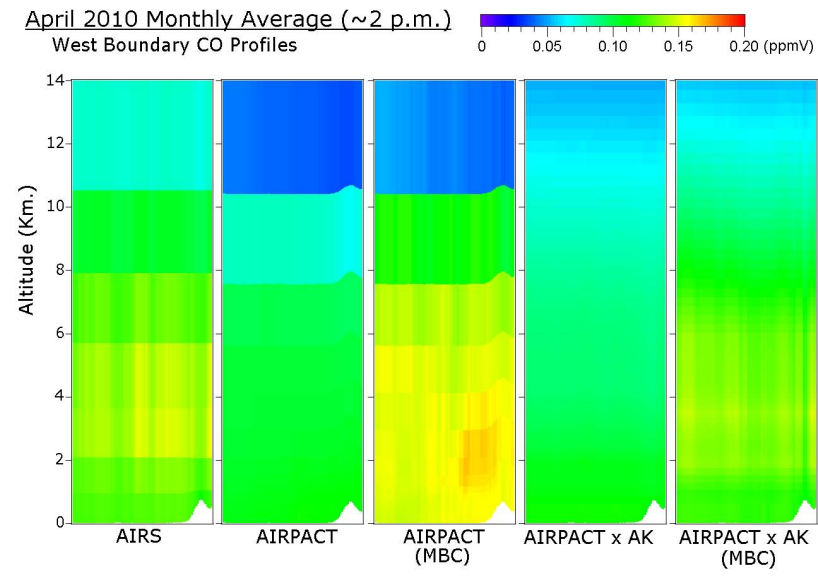

Fig. 12. April 2010 monthly average ( $\sim 02: 00$ p.m. PST) carbon monoxide profiles along the west border of AIRPACT-3 for (a) AIRS level-2 v5, (b) original AIRPACT-3, (c) AIRPACT-3 MBC, (d) original AIRPACT-3 convolved with the AIRS averaging kernel, and (e) AIRPACT-3 MBC convolved with the AIRS averaging kernel. Note that AIRPACT-3 values shown are the predicted CMAQ concentrations, and not boundary conditions themselves. For reference, $\mathrm{x}$-axes run from south to north: offshore northern California (left) to Vancouver Island (right).

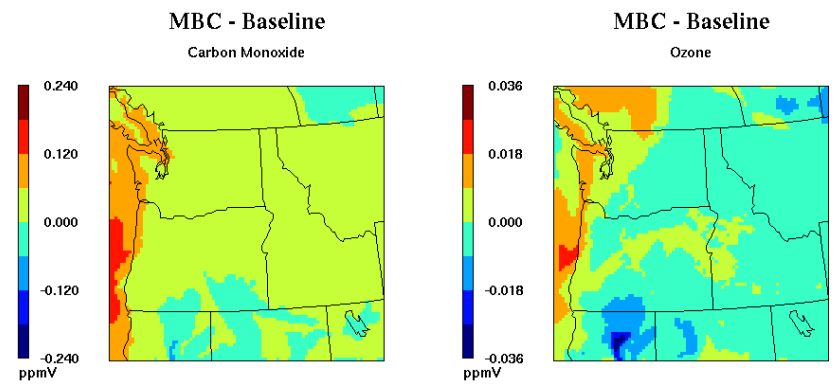

Fig. 13. Change in AIRPACT-3's predicted surface concentrations of carbon monoxide (left) and ozone (right) for the peak ozone hour (17 August 2010). Warm colors denote larger concentrations in the dynamic boundary conditions simulation (MBC) while cooler colors denote larger concentrations in the original AIRPACT-3 simulations (baseline).
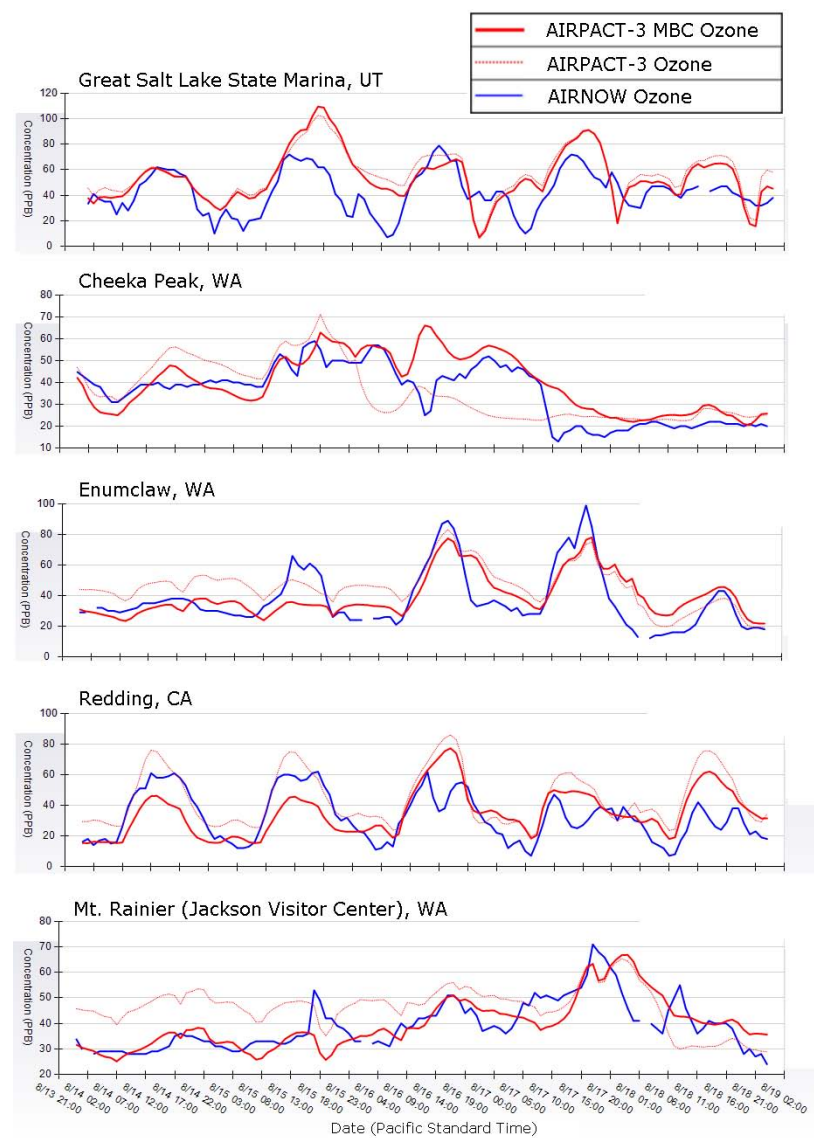

Fig. 14. AIRPACT-3's predicted surface concentrations of ozone and AIRNOW measurements at five sites during peak ozone in August 2010. Blue lines denote AIRNOW, solid red lines denote the new AIRPACT-3 MBC simulations, and dotted red lines denote the original AIRPACT-3 simulations with static boundary conditions. All times are in Pacific Standard Time. 


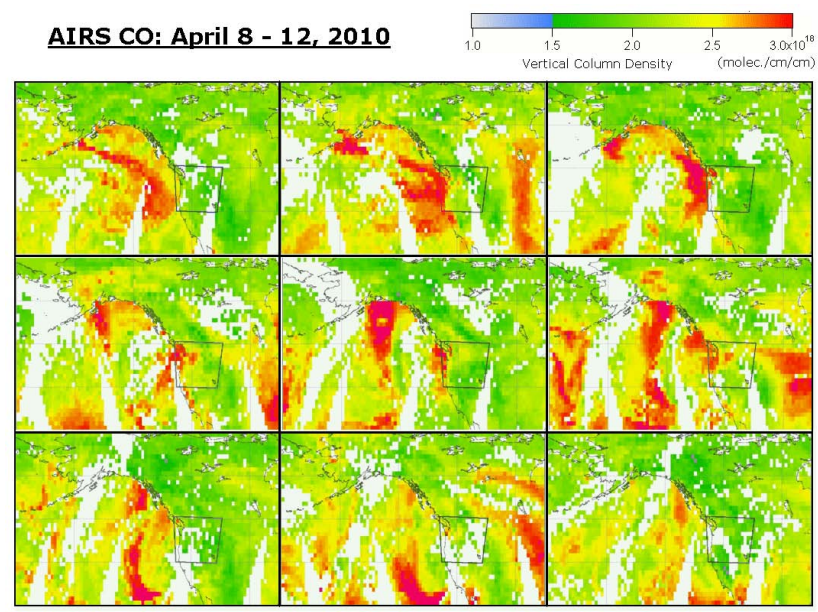

Fig. 15. AIRS carbon monoxide columns for 8-12 April over the Pacific Northwest from the AIRS level-3 data product. Borders of the AIRPACT-3 domain inserted for reference. Frames are $12 \mathrm{~h}$ apart and sequence from left to right, top to bottom.

resulting in elevated background concentrations off the coast of Vancouver Island and southern California (Fig. 15).

\section{Conclusions and future work}

NCAR's daily MOZART-4 forecasts with MOPITT CO assimilation have made it possible to upgrade AIRPACT-3 to a state-of-the-science method for specifying boundary conditions. Differences between the dynamic and original BCON illustrate how highly episodic trans-continental air pollution events are raising regional "background" levels of species such as carbon monoxide and ozone in the middle troposphere. This is especially a concern for areas with high surface elevation that already have an air quality problem.

Without applying the AIRS averaging kernel, the comparisons would lead us to believe that AIRPACT-3 has a CO column bias of $+10 \%$. However, application of the averaging kernels shows that the new dynamic boundary conditions have improved AIRPACT-3 performance considerably, changing the average CO column bias from $-25 \%$ to $+1.5 \%$. Furthermore, AIRPACT- 3 and AIRS show excellent agreement in vertical and horizontal distribution of CO. Ozone and other molecular species found in polluted air masses also have more realistic representations in the AIRPACT-3 MBC simulations. Summertime surface ozone predictions were affected most near the western borders of the AIRPACT-3 domain, especially for elevated areas near the coast. The surface ozone performance increased for most monitor locations in the domain with the MBC simulations, largely due to dynamic background ozone not being captured by the original simulations. The original monthly averaged boundary conditions were reasonable for ozone but did not have the spatial and temporal variability that the MBC simulations can deliver.

In the future, we plan to use correlations of $\mathrm{CO}$ to other species, as demonstrated by Jaffe and colleagues (http:// www.atmos.washington.edu/jaffegroup/modules/MBO/), in tandem with satellite products (i.e. AOD) and NCAR's global modeling to adjust the dynamic boundary conditions. This should be especially useful in discriminating active wildfires from long-range pollution episodes so that aerosols and other species associated with the events may be estimated (see Paton-Walsh et al., 2010).

\section{Supplementary material related to this article is available online at: http://www.atmos-chem-phys.net/12/ 5603/2012/acp-12-5603-2012-supplement.pdf.}

Acknowledgements. The National Center for Atmospheric Research is funded by the National Science Foundation. This research was made possible by grants from NASA for the NW-AIRQUEST Decision Support System (NNA06CN04A) and for use of satellite data products with the AIRPACT-3 regional air quality model (NNX11AE57G). The authors would like to thank and acknowledge Jeremy Avise, whose prior work was integral for this project. We would also like to thank Eric Maddy, Brad Pierce, Jack Chen, and Rodrigo Gonzalez-Abraham for their contributions to this work. NW-AIRQUEST provides support for the operation of the AIRPACT forecast system.

Edited by: B. N. Duncan

\section{References}

Al-Saadi, J., Soja, A. J., Pierce, R. B., Szykman, J., Wiedinmyer, C., Emmons, L., Kondragunta, S., Zhang, X., Kittaka, C., Schaack, T., and Bowman, K.: Intercomparison of near-real-time biomass burning emissions estimates constrained by satellite fire data, J. Appl. Remote Sens., 2, 021504, doi:10.1117/1.2948785, 2008.

Chen, J., Vaughan, J., Avise, J., O'Neill, S., and Lamb, B.: Enhancement and evaluation of the AIRPACT-3 ozone and PM2.5 forecast system for the Pacific Northwest, J. Geophys. Res., 113, D14305, doi:10.1029/2007JD009554, 2008.

Deeter, M. N., Edwards, D. P., Gille, J. C., Emmons, L. K., Francis, G., Ho, S.-P., Mao, D., Masters, D., Worden, H., Drummond, J. R., and Novelli P. C.: The MOPITT version 4 CO product: Algorithm enhancements, validation and long-term stability, J. Geophys. Res., 115, D07306, doi:10.1029/2009JD013005, 2010.

Emmons, L. K., Deeter, M. N., Gille, J. C., Edwards, D. P., Attié, J.-L., Warner, J., Ziskin, D., Francis, G., Khattatov, B., Yudin, V., Lamarque, J.-F., Ho, S.-P., Mao, D., Chen, J. S., Drummond, J., Novelli, P., Sachse, G., Coffey, M. T., Hannigan, J. W., Gerbig, C., Kawakami, S., Kondo, Y., Takegawa, N., Schlager, H., Baehr, J., and Ziereis, H.: Validation of Measurements of Pollution in the Troposphere (MOPITT) CO retrievals with aircraft in situ profiles, J. Geophys. Res., 109, D03309, doi:10.1029/2003JD004101, 2004. 
Emmons, L. K., Walters, S., Hess, P. G., Lamarque, J.-F., Pfister, G. G., Fillmore, D., Granier, C., Guenther, A., Kinnison, D., Laepple, T., Orlando, J., Tie, X., Tyndall, G., Wiedinmyer, C., Baughcum, S. L., and Kloster, S.: Description and evaluation of the Model for Ozone and Related chemical Tracers, version 4 (MOZART-4), Geosci. Model Dev., 3, 43-67, doi:10.5194/gmd3-43-2010, 2010.

Goldstein, A. H., Millet, D. B., McKay, M., Jaegl'e, L., Horowitz, L., Cooper, O., Hudman, R., Jacob, D. J., Oltmans, S., and Clarke, A.: Impact of Asian emissions on observations at Trinidad Head, California, during ITCT 2K2, J. Geophys. Res., 109, D23S17, doi:10.1029/2003JD004406, 2004.

Jaffe, D. A. and Ray, J.: Increase in surface ozone at rural sites in the western US, Atmos. Environ., 41, 5452-5463, 2007.

Jaffe, D. A., Anderson, T., Covert, D., Trost, B., Danielson, J., Simpson, W., Blake, D., Harris, J., and Streets, D.: Observations of ozone and related species in the northeast Pacific during the PHOBEA campaigns: 1 . Ground-based observations as Cheeka Peak, J. Geophys. Res., 106, 7449-7461, 2001.

Jaffe, D., Price, H., Parrish, D. D., Goldstein, A., and Harris, J.: Increasing background ozone during spring on the west coast of North America, Geophys. Res. Lett., 30, 1613, doi:10.1029/2003GL017024, 2003.

Jaffe, D., Prestbo, E., Swartzendruber, P., Weiss-Penzias, P., Kato, S., Takami, A., Hatakeyama, S., and Kajii, Y.: Export of atmospheric mercury from Asia, Atmos. Environ., 39, 3029-3038, 2005.

Herron-Thorpe, F. L., Lamb, B. K., Mount, G. H., and Vaughan, J. K.: Evaluation of a regional air quality forecast model for tropospheric $\mathrm{NO}_{2}$ columns using the OMI/Aura satellite tropospheric $\mathrm{NO}_{2}$ product, Atmos. Chem. Phys., 10, 8839-8854, doi:10.5194/acp-10-8839-2010, 2010.

Horowitz, L. W.: Past, present, and future concentrations of tropospheric ozone and aerosols: Methodology, ozone evaluation, and sensitivity to aerosol wet removal, J. Geophys. Res., 111, D22211, doi:10.1029/2005JD006937, 2006.

Horowitz, L., Walters, S., Mauzerall, D., Emmons, L., Rasch, P., Granier, C., Tie, X., Lamarque, J.-F., Schultz, M., Tyndall, G., Orlando, J., and Brasseur, G.: A global simulation of tropospheric ozone and related tracers: Description and evaluation of MOZART, version 2, J. Geophys. Res., 108, 4784, doi:10.1029/2002JD002853, 2003.

Houyoux, M., Vukovich, J., and Brandmeyer, J. E.: Sparse Matrix Operator Kernel Emissions (SMOKE) modeling system v2.1 user manual, University of North Carolina at Chapel Hill, available at: http://www.smoke-model.org/version2.1/html/ (last access: January 2012), 2005.

Lamarque, J.-F., Khattatov, B., Yudin, V., Edwards, D. P., Gille, J. C., Emmons, L. K., Deeter, M. N., Warner, J., Ziskin, D. C., Francis, G. L., Ho, S., Mao, D., Chen, J., and Drummond, J. R.: Application of a bias estimator for the improved assimilation of MOPITT carbon monoxide retrievals, J. Geophys. Res., 109, D16304, doi:10.1029/2003JD004466, 2004.

Liang, Q., Jaeglé, L., Jaffe, D. A., Weiss-Penzias, P., Heckman, A., and Snow, J. A.: Long-range transport of Asian pollution to the northeast Pacific: Seasonal variations and transport pathways of carbon monoxide, J. Geophys. Res., 109, D23S07, doi:10.1029/2003JD004402, 2004.
Liu, H., Jacob, D. J., Bey, I., Yantosca, R. M., Duncan, B. N., and Sachse, G. W.: Transport pathways for Asian pollution outflow over the Pacific: Interannual and seasonal variations, J. Geophys. Res., 108, 8786, doi:10.1029/2002JD003102, 2003.

Liwen, P., Gille, J., Edwards, D., Bailey, P., and Rodgers, C.: Retrieval of tropospheric carbon monoxide for the MOPITT experiment, J. Geophys. Res., 103, 32277-32290, 1998.

Maddy, E. S. and Barnet, C. D.: Vertical resolution estimates in version 5 of AIRS operational retrievals, IEEE T. Geosci. Remote, 46, 2375-2384, doi:10.1109/TGRS.2008.917498, 2008.

Mass, C. F., Albright, M., Ovens, D., Steed, R., MacIver, M., Grimit, E., Eckel, T., Lamb, B., Vaughan, J., Westrick, K., Storck, P., Colman, B., Hill, C., Maykut, N., Gilroy, M., Ferguson, S. A., Yetter, J., Sierchio, J. M., Bowman, C., Stender, R., Wilson, R., and Brown, W.: Regional Environmental Prediction over the Pacific Northwest, B. Am. Meteorol. Soc., 84, 1353-1366, 2003.

Olsen, E. T., Fishbein, E., Lee, S. Y., Manning, E., Maddy, E., and McMillan, W. W.: AIRS/AMSU/HSB Version 5 Level 2 Product Levels, Layers and Trapezoids, Retrieval Channel Sets, Jet Propulsion Laboratory, California Institute of Technology, Pasadena, CA, 2007a.

Otte, T. L. and Pleim, J. E.: The Meteorology-Chemistry Interface Processor (MCIP) for the CMAQ modeling system: updates through MCIPv3.4.1, Geosci. Model Dev., 3, 243-256, doi:10.5194/gmd-3-243-2010, 2010.

Paton-Walsh, C., Emmons, L. K., and Wilson, S. R.: Estimated total emissions of trace gases from the Canberra Wildfires of 2003: a new method using satellite measurements of aerosol optical depth \& the MOZART chemical transport model, Atmos. Chem. Phys., 10, 5739-5748, doi:10.5194/acp-10-5739-2010, 2010.

Rasch, P. J., Mahowald, N. M., and Eaton, B. E.: Representations of transport, convection, and the hydrologic cycle in chemical transport models: Implications for the modeling of short-lived and soluble species, J. Geophys. Res., 102, 28127-28138, 1997.

Rodgers, C.: Inverse Methods for Atmospheric Sounding: Theory and Practice, World Sci., Hackensack, NJ, 2000.

Skamarock, W. C., Klemp, J. B., Dudhia, J., O.Gill, D., Barker, D. M., Wang, W., and Powers, J. G.: A Description of the Advanced Research WRF Version 2, Boulder, Colorado, National Center for Atmospheric Research, 2005.

Tang, Y. H., Carmichael, G. R., Thongboonchoo, N., Chai, T. F., Horowitz, L. W., Pierce, R., Al-Saadi, J. A., Pfister, G., Vukovich, J. M., Avery, M. A., Sachse, G. W., Ryerson, T. B., Holloway, J. S., Atlas, E. L., Flocke, F. M., Weber, R. J., Huey, L. G., Dibb, J. E., Streets, D., and Brune, W. H.: Influence of lateral and top boundary conditions on regional air quality prediction: A multiscale study coupling regional and global chemical transport models, J. Geophys. Res., 112, D10S18, doi:10.1029/2006JD007515, 2007.

van der Werf, G. R., Randerson, J. T., Giglio, L., Collatz, G. J., Kasibhatla, P. S., and Arellano Jr., A. F.: Interannual variability in global biomass burning emissions from 1997 to 2004, Atmos. Chem. Phys., 6, 3423-3441, doi:10.5194/acp-6-3423-2006, 2006.

Yienger, J. J., Galanter, M., Holloway, T. A., Phadnis, M. J., Guttikunda, S. K., Carmichael, G. R., Moxim, W. J., and Levy, H.: The episodic nature of air pollution transport from Asia to North America, J. Geophys. Res., 105, 26931-26945, 2000. 
Zhang, L., Jacob, D. J., Boersma, K. F., Jaffe, D. A., Olson, J. R., Bowman, K. W., Worden, J. R., Thompson, A. M., Avery, M. A., Cohen, R. C., Dibb, J. E., Flock, F. M., Fuelberg, H. E., Huey, L. G., McMillan, W. W., Singh, H. B., and Weinheimer, A. J.:
Transpacific transport of ozone pollution and the effect of recent Asian emission increases on air quality in North America: an integrated analysis using satellite, aircraft, ozonesonde, and surface observations, Atmos. Chem. Phys., 8, 6117-6136, doi:10.5194/acp-8-6117-2008, 2008. 